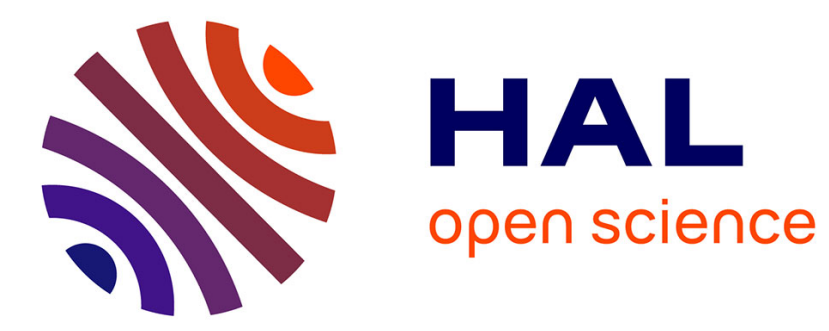

\title{
Light response curve methodology and possible implications in the 2 application of chlorophyll fluorescence to benthic diatoms
}

Rupert G. Perkins, Jean-Luc Mouget, Sébastien Lefebvre, Johann Lavaud

\section{- To cite this version:}

Rupert G. Perkins, Jean-Luc Mouget, Sébastien Lefebvre, Johann Lavaud. Light response curve methodology and possible implications in the 2 application of chlorophyll fluorescence to benthic diatoms. Marine Biology, 2006, 149, pp.703-712. 10.1007/s00227-005-0222-z . hal-01094638

\section{HAL Id: hal-01094638 \\ https://hal.science/hal-01094638}

Submitted on 12 Dec 2014

HAL is a multi-disciplinary open access archive for the deposit and dissemination of scientific research documents, whether they are published or not. The documents may come from teaching and research institutions in France or abroad, or from public or private research centers.
L'archive ouverte pluridisciplinaire HAL, est destinée au dépôt et à la diffusion de documents scientifiques de niveau recherche, publiés ou non, émanant des établissements d'enseignement et de recherche français ou étrangers, des laboratoires publics ou privés. 
2 Light response curve methodology and possible implications in the application of chlorophyll fluorescence to benthic diatoms

5 Perkins, R.G. ${ }^{1 *}$, Mouget, J-L. ${ }^{2}$, Lefebvre, S. ${ }^{3}$ and Lavaud, J. ${ }^{4}$

6

7 1. School of Earth, Ocean and Planetary Sciences, Cardiff University, Main Building,

8 Park Place, Cardiff, UK CF10 3YE

9 2. Laboratoire de Physiologie et Biochimie Végétales, Faculté des Sciences et

10 Techniques, Université du Maine, EA2663, Av. O. Messiaen, 72085 Le Mans Cedex

119 , France.

12 3. Laboratoire de Biologie et Biotechnologies Marines, Esplanade de la Paix, EA 962

13 Université de Caen, 14032 Caen Cedex, France.

14 4. Pflanzliche Ökophysiologie, Fachbereich Biologie, Universität Konstanz,

15 Universitätsstraße 10, 78457 Konstanz, Germany.

16

17

18

19

20

21

22

23 


\section{Abstract}

Chlorophyll $a$ fluorescence has been increasingly applied to benthic microalgae, especially diatoms, for measurements of electron transport rate (ETR) and construction of rapid light response curves (RLCs) for the determination of photophysiological parameters (mainly the maximum relative ETR $\left(\mathrm{rETR}_{\max }\right)$, the light saturation coefficient $\left(E_{\mathrm{k}}\right)$ and the maximum light use coefficient). Various problems with the estimation of ETR from the microphytobenthos have been identified, especially in situ. This study further examined the effects of light history of the cells and light dose accumulation during RLCs on the fluorescence measurements of ETR using the benthic diatom Navicula phyllepta. RLCs failed to saturate when using incremental increases in irradiance, however curves with decreasing irradiance did saturate. Patterns indicating photoacclimation in response to light histories were observed, with higher $\mathrm{rETR}_{\max }$ and $E_{\mathrm{k}}$, and lower $\alpha$, at high light compared to low light. However these differences could be negated by increasing the RLC irradiance duration from 30 to $60 \mathrm{~s}$. It is suggested that problems arose as a result of rapid fluorescence variations due to ubiquinone, $\mathrm{Q}_{\mathrm{A}}$, oxidation and non-photochemical chlorophyll fluorescence quenching, NPQ, which depended upon the light history of the cells and the RLCs accumulated light dose. Also, RLCs with irradiance duration of $10 \mathrm{~s}$ were shown to have an error possibly specific to the fluorimeter programming. It is suggested that RLCs, using a Diving-PAM fluorimeter on benthic diatoms, should be run using decreasing irradiance steps of $30 \mathrm{~s}$ duration. 


\section{Introduction}

Benthic microalgae communities, mainly composed of diatoms, inhabit shallow estuarine intertidal sediments where they are responsible for the major part of the photosynthetic primary production (MacIntyre et al., 1996). The light environment to which the microphytobenthos are exposed is highly variable due to the tidal regime, which expose the cells to a wide range of, and rapid changes between, levels of irradiance, together with a high spatial and temporal frequency of light fluctuations. Therefore, one the main challenges for microphytobenthic algae is to cope with fluctuations in irradiance, largely through avoidance of energy imbalance within the photosynthetic apparatus, and maintainance of an optimal irradiance to maximise photosynthetic productivity (Underwood and Kromkamp, 1999, Perkins et al 2002, Consalvey et al. 2005a). For this purpose, algae have evolved a number of mechanisms referred to as photoacclimation (MacIntyre et al. 2000, Raven and Geider, 2003).

To investigate the photosynthesis of the microphytobenthos, chlorophyll $a$ (Chl a) fluorescence measurements of electron transport rate (ETR) and related photophysiological parameters are being increasingly applied (Consalvey et al. 2005a). Studies have been used to compare measurements of primary productivity using different methodologies, principally carbon uptake (radio-labeled ${ }^{14} \mathrm{C}$ ), electron transport rate (Chl $a$ fluorescence) and oxygen evolution (oxygen electrodes) (Flameling \& Kromkamp 1998, Hartig et al. 1998, Barranguet and Kromkamp 2000, Perkins et al. 2001, 2002). Others have been confined solely to the use of Chl $a$ fluorescence as a proxy for primary productivity by measuring ETR (Kromkamp et al. 1998; Serôdio and Catarino 2000; Serôdio 2003; Serôdio et al. 2005a; Underwood et al. 2005) or as a proxy for algal biomass (Serôdio et al. 1997; Honeywill et al. 2002). 
The recent technique of rapid light response curves (RLCs), defined as very short (tens of seconds) light steps of different intensity, has been widely applied for the determination of ETR versus irradiance on different photosynthetic aquatic organisms like macro-and micro-algae, seagrasses and corals (Schreiber et al. 1997, Ralph et al. 1999, Kühl et al. 2001, Glud et al. 2002, Ralph and Gademann 2005). The short duration of each light step is an attempt to minimize the confounding effects of light acclimation encountered with 'steady-state' traditional light curves (Serôdio 2004, Serôdio et al. 2005a). RLCs have been used with success on microphytobenthos assemblages isolated from the field or directly in situ (Perkins et al. 2002, Serôdio et al. 2005a). However, the assessment of RLCs on intact biofilms can be disturbed, which may alter the calculation of ETR as a function of light intensity (Perkins et al. 2002). The two major sources of disturbance that have been identified are the attenuation of light in the sediment and the depth-integration of fluorescence emitted from sub-surface layers (Forster and Kromkamp 2004, Serôdio 2004), and the migration of the cells within the biofilm (Kromkamp et al. 1998, Perkins et al. 2002, Serôdio 2004). In addition, rapid as well as endogenous changes in photosynthesis activity, which modulate the Chl $a$ fluorescence emission, can potentially affect ETR measurements (Serôdio et al. 2005a). In particular, the red-ox state of $\mathrm{Q}_{\mathrm{A}}$, the primary PSII electron acceptor, and non-photochemical Chl $a$ fluorescence quenching (NPQ) have been shown to influence the fluorescence measurements in microphytobnethic diatoms (Consalvey et al. 2004, Serôdio et al. 2005a, 2005b). In this context, technical features of the RLCs, such as the length of each irradiance step, have been shown to be important for the assessment of ETR (Serôdio et al. 2005a). 
especially focused on the ability of the RLCs to relate the photoacclimation status through the assessment of ETR. By using algal cultures of the benthic diatom, Navicula phyllepta Kützing, we investigated the effect on the ETR/light relationship of: 1) the light history of the cells, 2) the RLCs light step duration and order (i.e. increasing or decreasing irradiance). The data obtained were compared with RLCs performed on separate replicates of the culture for each light step ('non sequential' light curves, N-SLCs) to assess the potential cumulative effect of rapid photoacclimation of the cells during the light curve itself. The results raise important questions with regard to potential errors in the measurement and interpretation of RLCs for cultured benthic diatoms, errors which may equally apply for in situ measurements.

\section{Methods}

Navicula phyllepta cultures

Navicula phyllepta was obtained from the microalgal culture collection of the Laboratoire de Biologie Marine (ISOMer, Nantes, France). Stock cultures were grown in an artificial seawater medium (Harrison et al., 1980) at low irradiance (20 $\mu$ mol photons $\mathrm{m}^{-2} \mathrm{~s}^{-1}, 6 \mathrm{~h} / 18 \mathrm{~h}$, light/dark photoperiod). The original medium was complemented following De Brouwer et al. (2002), with the addition of Fe- $\mathrm{NH}_{4}$ citrate (1.37 $\mu \mathrm{M}$ final concentration), $\mathrm{CuSO}_{4} 5 \mathrm{H}_{2} \mathrm{O}(0.04 \mu \mathrm{M}$ f.c.), folic acid (0.18 nM f.c. $)$, nicotinic acid (0.0325 $\mu \mathrm{M}$ f.c.), thymine (0.95 $\mu \mathrm{M}$ f.c.), Ca-d-pantothenate (8.39 $\mathrm{nM}$ f.c.) and inositol (1.11 $\mu \mathrm{M}$ f.c.). Experiments were run with cultures grown in semi-continuous culture mode (volume: $250 \mathrm{~mL}$, temperature: $15 \pm 1^{\circ} \mathrm{C}$ ) in Erlenmeyer flasks $(500 \mathrm{~mL})$ illuminated from below $\left(100 \mu \mathrm{mol}\right.$ photons $\mathrm{m}^{-2} \mathrm{~s}^{-1}$, 
$12514 \mathrm{~h} / 10 \mathrm{~h}$, light/dark photoperiod) by a high intensity discharge lamp (Osram HQI BT, $126400 \mathrm{~W})$.

131 Fluorescence measurements were made using a Diving-PAM fluorimeter (Walz,

132 Effeltrich, Germany). Sub-samples of $N$. phyllepta cultures were incubated at either

133 low or high light (LL or HL; 25 or $400 \mu \mathrm{mol}$ photons $\mathrm{m}^{-2} \mathrm{~s}^{-1}$ PPFD respectively), in a

134 stirred, temperature controlled $\left(15^{\circ} \mathrm{C}\right)$ chamber, for $60 \mathrm{~min}$. This light acclimation

135 period was staggered, so that each sub-sample had been exposed for exactly $60 \mathrm{~min}$

136 prior to measurement of each RLC. After light acclimation, the culture sub-sample

137 was transferred into a temperature controlled $\left(15^{\circ} \mathrm{C}\right)$ Hansatech DW2 chamber, with

138 continuous stirring to prevent settling. The Diving-PAM fibre optic probe was applied

139 to the top aperture of the chamber so that measurements were taken from cells

140 exposed to the actinic light level applied from the halogen internal light source, thus

141 minimising any light gradient effect (other apertures were darkened). Cultures were

142 dark-adapted for 5 min prior to RLCs, with measurements at 10, 30 and $60 \mathrm{~s}$ at each

143 light intensity. RLCs were performed with either incremental increases ('up') or

144 decreases ('down') in the actinic light intensity between 0 and $1850 \mu$ mol photons $\mathrm{m}^{-2}$

$145 \mathrm{~s}^{-1}$ PPFD. Light levels were measured using the Diving-PAM quantum meter, 146 corrected against a calibrated Li-Cor LI-189 quantum meter with a Q21284 quantum 147 sensor.

148 At each light level, effective photosystem II (PSII) quantum efficiency $149\left(F_{q}{ }^{\prime} / F_{m}{ }^{\prime}\right.$, Oxborough et al. 2000; Lawson et al. 2002; Perkins et al. 2002) was 150 measured by the saturation pulse technique, whereby a saturating light pulse of $1517,600 \mu \mathrm{mol}$ photons $\mathrm{m}^{-2} \mathrm{~s}^{-1}$ PPFD was applied for $400 \mathrm{~ms}$ to measure the maximum 
152 fluorescence yield, $F_{m}{ }^{\prime} \cdot F_{q}{ }^{\prime} / F_{m}{ }^{\prime}$ is equivalent to $\Delta F / F_{m}$ ' (Genty et al., 1989 ), however

$153 F_{q}{ }^{\prime}$ is preferred as it represents, not a change in fluorescence yield, but a difference

154 resulting from photosynthetic quenching of yield, hence the suffix $q$ (Oxborough et

155 al., 2000). $F_{q}{ }^{\prime} / F_{m}{ }^{\prime}$ was calculated as $\left(F_{m}{ }^{\prime}-F^{\prime}\right) / F_{m}$, where $F^{\prime}$ is the fluorescence

156 yield in the light adapted state, just prior to the application of the saturating pulse.

157 Hence $F_{q}{ }^{\prime} / F_{m}$ ' is equivalent to the Genty parameter in the light adapted state (Genty et

158 al. 1989). Relative electron transport rate (rETR) was then calculated as the product of

$159 F_{q}{ }^{\prime} / F_{m}{ }^{\prime}$ and PPFD/2 (Sakshaug et al. 1997; Perkins et al. 2001 2002).

160 The Diving-PAM has internal programmes allowing 8-step RLCs with

161 increasing light levels. Therefore, RLCs were performed using the remote control

162 functions in the WinControl software (Walz, Effeltrich, Germany) from a laptop

163 computer, so as to apply decreasing as well as increasing light levels covering 12 light

164 increments. This also enabled examination of the transient fluorescence kinetics, by

165 monitoring the $F^{\prime}$ ' signal in the chart mode, allowing determination of $F$ ' 'steady-

166 state' as well as examining changes in $F^{\prime}$ in response to application of each actinic

167 light level.

168 Prior to all sets of light curves, the Diving-PAM auto-zero function was set

169 using the Hansatech chamber filled with an equivalent volume of clear media. Light

170 calibration was also carried out before and after all light curves due to an observed

$17110 \%$ variation in halogen output over time, despite running the Diving-PAM from a

172 mains supply. As a result light levels differed between curves by up to $10 \%$, with this

173 variation accounted for in calculations of rETR.

174 Over-estimation of photochemical efficiency can occur when using the

175 Diving-PAM with low biomass culture which results in an $F^{\prime}$ signal below

176130 relative units (Walz Diving-PAM handbook). This low signal strength may also 
occur at exposure to high light due to high levels of non-photochemical fluorescence quenching (NPQ). Therefore the Diving-PAM gain setting was set to a maximum of 12 to avoid low values of $F^{\prime}$. However at such a high gain, the auto-zero function can also result in over-estimation of quantum efficiency. A large auto-zero value will be a greater proportion of $F^{\prime}$ compared to $F_{m}{ }^{\prime}$, when $F^{\prime}$ decreases as actinic light level increases. Mathematically, the same percentage change in $F^{\prime}$ and $F_{m}$ ' will therefore result in different values of $F_{q}{ }^{\prime} / F_{m}$ ' due to the weighted influence of the auto-zero. Therefore, only measurements with a low auto-zero ( $<40$ relative units) were used in the construction of RLCs.

\section{Non-sequential light response curves}

To remove the cumulative effect of light history experienced during a RLC, the above methods were modified by using a different replicate sub-sample of culture for each actinic light level. The range of light intensities was also extended up to $3200 \mu \mathrm{mol}$ photons $\mathrm{m}^{-2} \mathrm{~s}^{-1}$. In addition a further RLC data point was added, with measurements made when the fluorescence signal $F^{\prime}$ reached a constant level (as observed on the Win Control software chart function). This value of $F$ ', defined here as 'steady-state', was probably not a true steady-state due to time limitations and so was not defined as $F_{s}$.

Non-sequential light response curves (N-SLCs) and calculations were otherwise the same as for rapid RLCs, except that a first set of curves used cells maintained at $100 \mu \mathrm{mol}$ photons $\mathrm{m}^{-2} \mathrm{~s}^{-1} \mathrm{PPFD}$, with no photo-acclimation to high or low light. A second set of N-SLCs were then obtained using a different original semicontinuous culture of $N$. phyllepta, but incorporating the HL and LL photoacclimation 
202

period. These curves were not directly comparable to the preceding datasets, due to the change in source culture.

NPQ was calculated during N-SLCs, as $\left(F_{m}-F_{m}{ }^{\prime}\right) / F_{m}{ }^{\prime}$ (Krause and Weiss 1991; Lavaud et al. 2002a). $F_{m}$ ' was measured as described above, using application of the saturating pulse after 10,30 and $60 \mathrm{~s}$ at each irradiance, and when $F^{\prime}$ reached an approximate 'steady-state'. The maximum fluorescence yield in the dark adapted state, $F_{m}$, is more problematic to measure for diatoms, due to NPQ being maintained in the dark through processes such as chlororespiration (Jakob et al. 2001; Dijkman and Kroon 2002; Lavaud et al. 2002b), thus suppressing $F_{m}$ below its true value (Mouget and Tremblin 2002). The calculated values of NPQ therefore show relative changes, using an approximation of $F_{m}$ obtained after 5 min dark adaptation prior to each RLC.

\section{Statistical analysis}

RLCs of rETR against light intensity (PPFD) were constructed using the model of Eilers and Peeters (1988), estimating the maximum electron transport rate $\left(\mathrm{rETR}_{\max }\right)$, the maximum light use efficiency $(\alpha)$ and the light saturation coefficient $\left(E_{\mathrm{k}}\right)$ calculated as $\left(\mathrm{rETR}_{\max } / \alpha\right)$.

Curve fitting was achieved using the downhill simplex method of the NelderMead model, and standard deviation of parameters was estimated by a bootstrap method under Fortan 77 code (Press et al. 2003). All fittings were tested by analyses of variance $(\mathrm{P}<0.001)$, residues being tested for normality and homogeneity of variance, and parameters significance by Student t-test $(\mathrm{P}<0.05)$. RLCs and 
226 photosynthetic parameter comparisons were achieved using the method of Ratkowski 227 (1983) for non-linear models.

\section{Results}

Rapid light response curves

Rapid RLCs for low light (LL) and high light (HL) acclimated cultures of $N$. phyllepta showed saturation and down regulation when irradiance was reduced from

$2351850 \mu \mathrm{mol}$ photons $\mathrm{m}^{-2} \mathrm{~s}^{-1}$ (Fig. 1A,B: 10, 30 and 60 down). In contrast, when 236 irradiance was incrementally increased, light saturation and photoinhibition (Fig. 237 1A,B: 10, 30 and 60 up) did not occur. When irradiance was increased or reduced, 238 rETR above $500 \mu \mathrm{mol}$ photons $\mathrm{m}^{-2} \mathrm{~s}^{-1}$ increased in proportional to the increase in 239 length of time at each light level. Calculated values of $\mathrm{rETR}_{\max }, \alpha$ and $E_{\mathrm{k}}$ obtained from RLCs with decreasing

241 light levels were compared between HL and LL cultures (Fig. 2). 10, 30 and $60 \mathrm{~s}$ 242 RLCs for HL cultures showed $\mathrm{rETR}_{\max }$ and $\mathrm{E}_{\mathrm{k}}$ higher and $\alpha$ lower than LL cultures 243 ( $\mathrm{P}<0.001$; Fig. 2A,B,C). Thus photoacclimation occurred within the $1 \mathrm{~h}$ light 244 treatment period. $\mathrm{rETR}_{\max }$ increased significantly with the length of irradiance step for 245 low light and high light $(\mathrm{P}<0.01)$ acclimated cultures, whereas $\alpha$ showed no 246 significant correlation with length of irradiance step. $E_{\mathrm{k}}$, due the nature of its 247 derivation from $\left(\mathrm{rETR}_{\max } / \alpha\right)$ showed the same increase as $\mathrm{rETR}_{\max }$ as a function of 248 lengthening irradiance step $(\mathrm{P}<0.001)$.

249 RLCs with increasing light levels did not saturate for LL (Fig. 1A: 60 s) and 250 HL cultures (Fig. 1B: 10, 30 and 60 s), preventing calculation of $\mathrm{rETR}_{\max }$ and $E_{\mathrm{k}}$. 251 Estimation of $\alpha$ indicated photoacclimation patterns similar to the decreasing 
252 irradiance RLCs. LL cultures had significant higher values of $\alpha$ compared to HL 253 cultures $(\mathrm{P}<0.001) .10$ and $30 \mathrm{~s}$ LCRs for LL cultures just reached saturation, and 254 showed the same pattern in rETR $_{\max }$ observed for decreasing RLCs, with a significant 255 increase in $\mathrm{rETR}_{\max }$ (165 to 235 rel. units from 10 to $30 \mathrm{~s}$ respectively), an increase in $256 E_{\mathrm{k}}$ (319 to $439 \mu \mathrm{mol}$ photons $\mathrm{m}^{-2} \mathrm{~s}^{-1}$ PPFD), but no change in $\alpha$ (0.52 rel. units).

Non-sequential light response curves

Separate replicate N. phyllepta cultures used for each light level (Fig. 3)

261 resulted in N-SLCs with similar patterns as rapid RLCs (Fig. 1). rETR increased 262 significantly with length of irradiance step $(\mathrm{P}<0.001)$ at irradiances above $300 \mu \mathrm{mol}$ 263 photons $\mathrm{m}^{-2} \mathrm{~s}^{-1}$, with correspondingly higher $\mathrm{rETR}_{\max } \cdot 10,30$ and $60 \mathrm{~s}$ RLCs all 264 showed light saturation and down regulation, whereas light curves when $F^{\prime}$ was 265 allowed to reach an apparent 'steady-state' at each light intensity, did not saturate. No 266 steady state data point was possible at $1850 \mu \mathrm{mol}$ photons $\mathrm{m}^{-2} \mathrm{~s}^{-1}$ as photosynthetic 267 down regulation (presumably NPQ) resulted in a Chl $a$ fluorescence yield ( $F^{\prime}$ ) below 268 the minimum value of 130 relative units required for accurate measurement of $269 F_{q}{ }^{\prime} / F_{m}{ }^{\prime}$.

270 N. phyllepta (a different culture from that used above and so not directly 271 comparable) was then acclimated to either low $\left(25 \mu \mathrm{mol}\right.$ photons $\left.\mathrm{m}^{-2} \mathrm{~s}^{-1}\right)$ or high 272 (400) light as above, prior to RLCs with different replicate cultures used for each light 273 intensity (Fig. 4). There were significant differences between the curves $(\mathrm{P}<0.001)$, 274 HL and LL cultures showed a significant increase in rETR proportional to an increase 275 in time at each irradiance step, except between 10 and 30 s HL, 30 and 60 s HL and 276 between steady state HL and LL RLCs. 
Despite changing replicate cultures for each light level, the same patterns were

278 observed as for the rapid RLCs (Fig. 1). HL acclimated cultures had significant 279 greater rETR $_{\max }\left(\mathrm{P}<0.001\right.$, Fig. 5A), and higher $E_{\mathrm{k}}(\mathrm{P}<0.001$, Fig. 5C) than LL 280 acclimated cultures. There were no significant differences for $\alpha(\mathrm{P}>0.05$; Fig. 5B). 281 However the difference in $\mathrm{rETR}_{\max }$ between HL and LL cells declined as the time at 282 each RLC increment increased. There was a significant increase in $\mathrm{rETR}_{\max }$ and $E_{\mathrm{k}}$ 283 with the length of irradiance step for low light and high light acclimated cultures $284(\mathrm{P}<0.001)$; $\alpha$ showed no significant differences for both LL and HL cultures $(\mathrm{P}>0.05)$.

\section{Chl a fluorescence and $N P Q$ kinetics}

288 An example of the fluorescence kinetics obtained at irradiance steps above $300 \mu \mathrm{mol}$ 289 photons $\mathrm{m}^{-2} \mathrm{~s}^{-1}$ is reproduced (Fig. 6) showing the position at which saturation pulses 290 were applied. The example is for a low-light culture $\left(25 \mu \mathrm{mol} \mathrm{m} \mathrm{m}^{-2} \mathrm{~s}^{-1}\right)$, transferred to $291370 \mu \mathrm{mol} \mathrm{m}^{-2} \mathrm{~s}^{-1}$. At $10 \mathrm{~s}$ the comparatively slow data acquisition time of the Diving292 PAM fluorimeter (compared to the rapid induction of fluorescence quenching) 293 resulted in an under-estimation of $F_{q}{ }^{\prime} / F_{m}$ '. This resulted from the high rate of

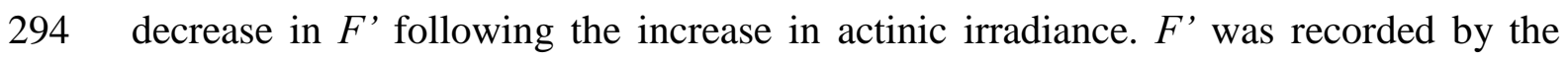
295 Diving-PAM prior to a further decrease before the measurement of $F_{m}$ '. $F^{\prime}$ and $F_{m}$ ' 296 were therefore recorded at different times, resulting in under-estimation of $F_{m}$, 297 relative to $F^{\prime}$ so that values of $F_{q}{ }^{\prime} / F_{m}$ ' were underestimated and often values of zero 298 were reported. $10 \mathrm{~s}$ light curves would then result in under-estimation of rETR above $299300 \mu \mathrm{mol}$ photons $\mathrm{m}^{-2} \mathrm{~s}^{-1}$ PPFD. This was most obvious for HL cultures, which 300 showed a more rapid decline in $F^{\prime}$ compared to LL cultures (data not shown). The 301 magnitude of the increase in $F$, on the application of the actinic light and the rate of 
302 decline after the peak in $F^{\prime}$ both increased as irradiance increased above $300 \mu \mathrm{mol}$ 303 photons $\mathrm{m}^{-2} \mathrm{~s}^{-1}$.

304 Above $300 \mu \mathrm{mol}$ photons $\mathrm{m}^{-2} \mathrm{~s}^{-1}$, NPQ was induced rapidly during RLCs, with 305 relatively high levels after $60 \mathrm{~s}$ at each irradiance, for both LL and HL acclimated 306 cultures (Fig. 7). While the amplitude of NPQ increased with illumination time for LL 307 cultures, it remained relatively similar for HL cultures. LL cultures (Fig. 7A) had 308 similar or lower levels of NPQ compared to HL cultures (Fig. 7B) after 10, 30 and 60 309 s, but higher NPQ at 'steady-state' (insert, Fig. 7B).

\section{Discussion}

313 The aims of the study were to determine the effects of light history prior to, and 314 accumulated light dose during, a light response curve (RLC) obtained using Chl $a$

315 fluorescence. It was expected that the light dose experienced by the algal cells over 316 different time scales during RLCs, would affect the Chl $a$ fluorescence measurements 317 obtained, and hence modify the resulting RLCs and photophysiological parameters 318 derived. The data obtained raise important questions with regard to the measurement 319 and interpretation of Chl $a$ fluorescence rapid RLCs. The primary question is, what is 320 being measured for light curves of different length of actinic irradiance steps?

321 The data reported here suggest two stages of photoacclimation. Firstly, the 322 acclimation resulting from exposure to low and high irradiance prior to RLCs, 323 effectively the type of photoacclimation that a RLC attempts to detect. Secondly, the 324 'acclimation' during the RLCs themselves; which RLC methodology should avoid. In 325 addition, the limitations of available methodology must also be considered. 
330 RLCs with incremental decreases in irradiance showed saturation and a decrease in $331 \mathrm{rETR}_{\max }$ at higher irradiance due to photoinhibition (Fig. 1). In contrast, RLCs with 332 increasing irradiance often did not saturate. This raises the first issue of RLCs 333 methodology: the effect of accumulated light dose during the light curve, dependent 334 upon the order of irradiances ('up' or 'down') and the duration of each step (from $10 \mathrm{~s}$ 335 to $2-3 \mathrm{~min})$.

336 With increasing irradiance, there is an accumulative effect of light dosage 337 resulting in progressive induction, occurring on a time scale of 10's of seconds, of the 338 different components of the photosynthetic apparatus. Ubiquinone $\left(\mathrm{Q}_{\mathrm{A}}\right)$ oxidation, the 339 rate limiting step in electron transport (Dau 1994) would have been faster for 340 increasing irradiance light curves due to induction of more rapid photochemical 341 energy transfer. Also, induction of non-photochemical Chl $a$ fluorescence quenching, 342 NPQ will have increased proportionally to the light dose experienced during the RLC. 343 In diatoms, the photosynthetic translocation of protons across the thylakoid membrane 344 has been linked to energy dependent NPQ (Ting \& Owens 1993; Lavaud et al. 2002c) 345 associated with xanthophyll pigment synthesis (Arsalane et al. 1994; Olaizola et al. 346 1994; Lavaud et al. 2002a 2003 2004; Serôdio et al. 2005b). This process generates a 347 photoprotective dissipation of excess energy in photosystem II (PSII) reducing the Chl $348 a$ fluorescence yield, on a time scale of 10's of seconds (MacIntyre et al. 2000; 349 Lavaud et al. 2002a 2004; Raven and Geider 2003). Hence, QA oxidation and NPQ 350 will affect in complex ways, the measurement of effective PSII quantum efficiency 351 and resultant calculation of (r)ETR. 
Increasing the duration of each incremental irradiance step was also seen to

353 induce photoacclimation. As the length of each step increased from 10 to $60 \mathrm{~s}$ rETR

354 increased proportionally, often resulting in a lack of saturation for RLCs with

355 increasing irradiance. Above $500 \mu \mathrm{mol}$ photons $\mathrm{m}^{-2} \mathrm{~s}^{-1}$, NPQ increased in importance, 356 and the duration for each irradiance step increased the extent of NPQ (Fig. 7). In $357 N$. phyllepta, $\mathrm{Q}_{\mathrm{A}}$ oxidation was the primary cause of the change in fluorescence yield 358 for RLCs with $10 \mathrm{~s}$ steps, however for $30 \mathrm{~s}$ and above, the level of NPQ became most 359 significant. As discussed below, the relative importance of $\mathrm{Q}_{\mathrm{A}}$ oxidation and NPQ is 360 species and light history dependent, and in diatoms the relationship between PSII 361 redox-state and NPQ is species specific (Ruban et al. 2004; Lavaud unpublished 362 results).

For decreasing irradiance steps, the accumulative light dose effect described 364 above was reduced relative to increasing irradiance RLCs. However, decreasing the 365 irradiance and hence immediate exposure to high irradiance did not appear to induce 366 photodamage. Two observations support this, the low amplitude of NPQ for 10 and $36730 \mathrm{~s}$ illumination duration at high irradiances, and the fact that rETR below $500 \mu \mathrm{mol}$ 368 photons $\mathrm{m}^{-2} \mathrm{~s}^{-1}$ was similar to that obtained with increasing irradiance. The use of 369 decreasing irradiance therefore reduces the over-estimation of rETR and is likely to be 370 more representative of the photophysiological state of the diatom cells prior to 371 application of the RLC, which is the state that the RLC aims to ascertain.

372 Despite changing the culture used for each irradiance step (N-SLCs), the same 373 patterns in data were observed as for rapid RLCs (Fig. 3, 4). rETR increased as a 374 function of the length of irradiance during the light curve, such that even when $F$ ' was 375 allowed to reach an approximation of 'steady-state', RLCs failed to saturate. The N376 SLCs indicate that the effect of light dose on the fluorescence measurements occurred 
rapidly, within the duration of each irradiance step. This observation confirms the impact of combined $\mathrm{Q}_{\mathrm{A}}$ redox state and NPQ on the Chl $a$ fluorescence kinetics and acquisition of $F^{\prime}$ and $F m^{\prime}$ for the calculation of rETR (see Fig. 6).

Ralph and Gademann (2005) conducted a recent similar investigation on the higher aquatic plant Zostera marina. They did not report a lack of saturation of the rETR curves, but in some cases did report a lack of down regulation post saturation. This lack of down regulation occurred for plants after low light treatment, and Ralph and Gademann (2005) suggested that their capacity for down regulation was exceeded. This differs from the data reported in the present study, where a lack of saturation in rETR was greater for high light compared to low light treatments, despite a higher capacity for NPQ in the former. We suggest that the lack of saturation of RLCs observed with $N$. phyllepta is an additional indication (see also Ruban et al. 2004) that rapid photoacclimatory processes occur in diatoms which can greatly affect fluorescence measurements, and especially the velocity of fluorescence transients (Ruban et al. 2004). Rapid processes known to occur to a higher extent and with more rapid induction kinetics in diatoms are the xanthophyll cycle (Jakob et al 2001; Lavaud et al 2004), NPQ (Lavaud et al. 2002a; Ruban et al 2004, Serôdio et al. 2005b) and the PS II electron cycle (Lavaud et al 2002b).

\section{The effect of light history on RLC interpretation}

The effects of the order and the duration of each RLC irradiance step were greatest for high light (HL) acclimated cultures (Fig. 1, 4). The light history, to which the cells were exposed, modified the speed of response of photochemistry to short changes in irradiance. HL cells had a greater capability to respond quickly to an increase in 
402 irradiance, most likely due to a greater availability in electron acceptors from 403 photochemical reactions, increasing the speed of $\mathrm{Q}_{\mathrm{A}}$ oxidation. The more rapid 404 kinetics for NPQ in HL cells can be explained by the basal level of NPQ developed 405 after $1 \mathrm{~h}$ exposure at $400 \mu \mathrm{mol}$ photons $\mathrm{m}^{-2} \mathrm{~s}^{-1}$, which did not relax during the $5 \mathrm{~min}$ 406 dark adaptation (Lavaud et al. 2002c; Ruban et al. 2004) In diatoms, NPQ amplitude 407 and kinetics are closely related to the amount of xanthophylls (Casper-Lindley and 408 Bjorkman 1998; Lavaud et al. 2002a 2002c), and are dependent upon light history 409 (Willemoes and Monas 1991; Mouget et al. 1999 2004; Lavaud et al. 2003), the state 410 of growth (Arsalane et al. 1994) and the species (Lavaud et al. 2004; Serôdio et al. $4112005 \mathrm{~b}$ ). Thus, all these aspects have to be taken into account in the potential effects of 412 NPQ during the RLC acquisition and interpretation.

Consequences for photophysiological parameters calculated from the RLCs

An expected pattern was observed when comparing $\mathrm{rETR}_{\max }, \alpha$ and $E_{\mathrm{k}}$ between HL and LL cultures (Fig. 2). The $1 \mathrm{~h}$ acclimation resulted in higher $\mathrm{rETR}_{\max }$ and $E_{\mathrm{k}}$ and lower $\alpha$ for HL compared to LL cells. Higher $\mathrm{rETR}_{\max }$ and $\mathrm{E}_{\mathrm{k}}$ are typical

419 for high light acclimated cells which have modified their light harvesting to utilise the 420 high levels of light to which they are exposed. Conversely, low light acclimated cells modify their photophysiology to maximise light harvesting efficiency and hence have

422 higher values of $\alpha$. However the light dose effect experienced during the RLCs 423 reduced or even negated these differences in rETR $_{\max }$. Similarly, for N-SLCs, the 424 differences in photophysiological parameters reduced as a function of increasing 425 length of each irradiance period. As a result, no difference was observed in $\mathrm{rETR}_{\max }$ by 'steady-state' (Fig. 5). This implies that long irradiance steps caused a photo-dose 
effect that reduced or even negated the real level of $1 \mathrm{~h}$ photoacclimation. It remains surprising though that cultures of N. phyllepta acclimated to 25 or $400 \mu$ mol photons $\mathrm{m}^{-2} \mathrm{~s}^{-1}$ did not saturate at $1850 \mu \mathrm{mol}$ photons $\mathrm{m}^{-2} \mathrm{~s}^{-1} . N$. phyllepta may have a high capacity to respond quickly to high light, probably through regeneration of ADP and $\mathrm{NADP}^{+}$and as a result of alternative electron pathways known to be active in diatoms (Caron et al. 1987; Lavaud et al. 2002b; Wilhelm et al. 2004). This is possibly a common feature of benthic diatoms, which may often experience rapid variations in incident light intensity.

Although the dataset was obtained from measurements on diatom cells in culture, the data suggest possible ecological implications with regard to diatom acclimation to light environment fluctuation in situ (Serôdio et al. 2005b). It would appear that $N$. phyllepta has a high ability to acclimate quickly to increasing irradiance. This would obviously be an advantage to cells inhabiting an open mudflat environment in which rapid changes could occur, e.g. as a result of cloud induced light flecking. Any energy dependent photoprotective acclimation, being more rapid than downward migration, would not only precede migration (Underwood et al., 2005) should high irradiance persist, but would also prevent wasteful short-term migrations requiring production and excretion of extracellular polymeric substances (carbohydrates generically described as EPS) used in migration (Consalvey et al. $2005 \mathrm{~b}$ and references there-in).

\section{Specificity of the RLCs acquisition with the Diving-PAM methodology}

Analysis of the fluorescence kinetics from N. phyllepta indicated an aspect of methodology, which may be particular to the Diving-PAM, and which can generate an 
452 error in the measurement of $F_{m}$ ' and hence rETR for $10 \mathrm{~s}$ irradiance steps (see the 453 description in the Results section, Fig. 6). To summarise, the time delay between 454 measurement of $F^{\prime}$ and the corresponding $F_{m}$ ' used in calculation of the quantum 455 efficiency resulted (during this study) in an under-estimation of $F_{m}$ ' relative to $F^{\prime}$ and 456 hence a falsely low efficiency. The example illustrated was for a low light culture at $45725 \mu \mathrm{mol} \mathrm{m} \mathrm{m}^{-1}$, transferred to $370 \mu \mathrm{mol} \mathrm{m} \mathrm{m}^{-2}$. This is an abrupt change, however the 458 effect was greatest for HL acclimated cultures and at high irradiances, when the rate 459 decay in $F^{\prime}$ (presumably resulting from interaction between $\mathrm{Q}_{\mathrm{A}}$ oxidation and NPQ 460 induction) was greatest. As such the level of this error is a function of light dose and 461 hence the light history to which the cells were exposed. This problem was not 462 encountered with the higher aquatic plant Zostera (Ralph and Gademann 2005) 463 presumably because the transients in fluorescence yield in plants are slower than in 464 diatoms, although NPQ relaxation is slower in diatoms (Ruban et al. 2004).

\section{Conclusions}

467 The present work indicates that light dose and light history strongly affect 468 fluorescence measurements used in RLC acquisition. These features have to be taken 469 into account in the acquisition and interpretation of Chl $a$ fluorescence RLCs. For 470 cultured benthic diatoms, and presumably for in situ mixed biofilms for the same 471 reasons, extreme care should be taken in choice of light curve methodology. 472 Parameters measured will be functions of light history and light exposure during the 473 light curve itself and the extent of this will in turn be dependent upon the light history 474 prior to the RLC. It is suggested that it is not always possible to answer the question 475 posed above: what is being measured for light curves of different length of actinic 476 irradiance? It is not possible to extrapolate these results to make general comments for 
477 all diatom species, nor to say that the changes suggested will occur for in situ 478 measurements. Indeed, no methodology is perfect and in many cases measurement 479 itself induces a change, thus making the commonly stated "non-intrusive" nature of 480 fluorescence measurements incorrect. For example, an increasing RLC induces 481 photoacclimation, however a decreasing RLC will allow dissipation of 482 photophysiological state (e.g. high light induced NPQ) as light level is reduced: 483 neither method is devoid of experimental error. However it is suggested that the 484 changes induced during a RLC should be carefully considered during interpretation of 485 results. In general, RLCs of $60 \mathrm{~s}$ or those with increasing incremental irradiance steps 486 may not detect differences in photophysiological state caused by light history, 487 differences that RLCs aim to determine. Conversely RLCs with short irradiance steps 488 may result in errors due to rapid NPQ induction and $\mathrm{Q}_{\mathrm{A}}$ oxidation, especially for 489 diatom cells exposed to high light or a high-accumulated light dose history. Overall, 490 re-programming of the Diving-PAM fluorimeter to enable RLCs with decreasing 491 irradiance levels is advised, and RLCs of $30 \mathrm{~s}$ at each irradiance step may be optimal 492 for use with benthic diatoms. 


\section{References}

495 Arsalane W, Rousseau B, Duval J-C (1994) Influence of the pool size of the 496 xanthophyll cycle on the effects of light stress in a diatom: competition between 497 photoprotection and photoinhibition. Photochem Photobiol 60: 237-243

498

499 Barranguet C, Kromkamp J (2000) Estimating primary production rates from 500 photosynthetic electron transport in estuarine microphytobenthos. Mar Ecol Prog Ser $501 \quad 204: 39-52$

503 Casper-Lindley C, Björkman O (1998) Fluorescence quenching in four unicellular 504 algae with different light-harvesting and xanthophyll-cycle pigments. Photosynth Res 505 56: $277-289$

507 Caron L, Berkaloff C, Duval J-C, Jupin H (1987) Chlorophyll fluorescence transients 508 from the diatom Phaeodactylum tricornutum: relative rates of cyclic phosphorylation 509 and chlororespiration. Photosynth Res 11: 131-139

511 Consalvey M, Jesus B, Perkins RG, Brotas V, Underwood GJC, Paterson DM (2004) 512 Monitoring migration and measuring biomass in benthic biofilms: the effects of 513 dark/far-red adaptation and vertical migration on fluorescence measurements. 514 Photosynth Res 81: 91-101

516 Consalvey M, Perkins RG, Paterson DM, Underwood GJC (2005a) PAM 517 fluorescence: a beginners guide for benthic diatomists. Diatom Res 20: 1-22 
519 Consalvey M, Paterson DM, Underwood GJC (2005b) The ups and downs of life in a

520 benthic biofilm: migration of benthic diatoms. Diatom Res 19 :181-202

522 Dau H (1994) Molecular mechanisms and quantitative models of variable 523 photosystem II fluorescence. Photochem Photobiol 60: 1-23

525 De Brouwer JFC, Wolfstein K, Stal LJ (2002) Physical characterization and diel 526 dynamics of different fractions of extracellular polysaccharides in an axenic culture of 527 a benthic diatom. Eur J Phycol 37: 37-44

529 Demers S, Roy S, Gagnon R, Vignault C (1991) Rapid light-induced changes in cell 530 fluorescence and in xanthophyll-cycle pigments of Alexandrium excavatum 531 (Dinophyceae) and Thalassiosira pseudonana (Bacillariophyceae): a photo-protection 532 mechanism. Mar Ecol Prog Ser 76: 185-193 Dijkman NA, Kroon BMA (2002) Indications for chlororespiration in relation to light regime in the marine diatom Thalassiosira weissflogii. J Photochem Photobiol B 66: $179-187$

538 Eilers PHC, Peeters JCH (1988) A model for the relationship between light intensity 539 and the rate of photosynthesis in phytoplankton. Ecol Model 42: 199-215

541 Flameling IA, Kromkamp J (1998) Light dependence of quantum yields for PSII 542 charge separation and oxygen evolution in eucaryotic algae. Limnol Oceanogr 43: $543 \quad 284-297$ 
545 Genty B, Briantais JM, Baker NR (1989) The relationship between the quantum yield

546 of photosynthetic electron transport and quenching of chlorophyll fluorescence.

547 Biochim Biophys Acta 990: 87-92

548

549 Gévaert F, Créach A, Davoult D, Migné A, Levavasseur G, Arzel P, Holl A-C,

550 Lemoine Y (2003) Laminaria saccharina photosynthesis measured in situ:

551 photoinhibition and xanthophyll cycle during a tidal cycle. Mar Ecol Prog Ser 247:

$552 \quad 43-50$

553

554 Glud RN, Kühl M, Wenzhöfer F, Rysgaard S (2002) Benthic diatoms of a high Arctic

555 fjord (Young Sound, NE Greenland): importance for ecosystem primary production.

556 Mar Ecol Prog Ser 238: 15-29

557

558 Harker M, Berkaloff C, Lemoine Y, Britton G, Young AJ, Duval J-C, Rmiki N-E,

559 Rousseau B (1999) Effects of high light and desiccation on the operation of the

560 xanthophyll cycle in two marine brown algae. Eur J Phycol 34: 35-42

562 Harrison PJ, Waters RE, Taylor FJR (1980) A broad spectrum artificial seawater

563 medium for coastal and open ocean phytoplankton. J Phycol 16: 28-35

564

565 Hartig P, Wolfstein K, Lippemeier S, Colijn F (1998) Photosynthetic activity of

566 natural microphytobenthos populations measured by fluorescence (PAM) and ${ }^{14} \mathrm{C}$ -

567 tracer methods: a comparison. Mar Ecol Prog Ser 166: 53-62 
569 Honeywill C, Paterson DM, Hagerthey SE (2002) Determination of

570 microphytobenthic biomass using pulse amplitude modulated minimum fluorescence.

$571 \quad$ Eur J Phycol 37: 485-492

572

573 Jakob T, Goss R, Wilhelm C (2001) Unusual pH-dependence of diadinoxanthin de-

574 epoxidase activation causes chlororespiratory induced accumulation of diatoxanthin in 575 the diatom Phaeodactylum tricornutum. J Plant Physiol 158: 383-390

576

577 Kromkamp J, Barranguet C, Peene J (1998) Determination of microphytobenthos

578 PS II quantum efficiency and photosynthetic activity by means of variable chlorophyll

579 fluorescence. Mar Ecol Prog Ser 162: 45-55

580

581 Kühl M, Glud RN, Borum J, Roberts R, Rysgaard S (2001) Photosynthetic 582 performance of surface-associated algae below sea ice as measured with a pulse583 amplitude modulated (PAM) fluorometer and $\mathrm{O}_{2}$ microsensors. Mar Ecol Prog Ser $584 \quad 223: 1-14$

585

586 Lavaud J, Rousseau B, van Gorkom HJ, Etienne A-L (2002a) Influence of the 587 diadinoxanthin pool size on photoprotection in the marine planktonic diatom 588 Phaeodactylum tricornutum. Plant Physiol 129: 1398-1406

590 Lavaud J, van Gorkom HJ, Etienne A-L (2002c) Photosystem II electron transfer 591 cycle and chlororespiration in planktonic diatoms. Photosynth Res 74: 51-59 
593 Lavaud J, Rousseau B, Etienne A-L (2002c) In diatoms, a transthylakoid proton 594 gradient alone is not sufficient to induce a non-photochemical fluorescence 595 quenching. FEBS Letters 523: 163-166

596

597 Lavaud J, Rousseau B, Etienne A-L (2003) Enrichment of the light-harvesting 598 complex in diadinoxanthin and implications for the non-photochemical fluorescence 599 quenching in diatoms. Biochem 42: 5802-5808

600

601 Lavaud J, Rousseau B, Etienne A-L (2004) General features of photoprotection by 602 energy dissipation in planktonic diatoms (Bacillariophyceae). J Phycol 40: 130-137

603

604 Lawson T, Oxborough K, Morrison JIL, Baker NR (2002) Responses of 605 photosynthetic electron transport in stomatal guard cells and mesophyll cells in intact 606 leaves to light, $\mathrm{CO}_{2}$, and humidity. Plant Physiol 128: 52-62

607

608 MacIntyre HL, Geider RJ, Miller DC (1996) Microphytobenthos: The ecological role 609 of the 'secret garden' of unvegetated, shallow-water marine habitats. I-Distribution, 610 abundance and primary production.

611

612 MacIntyre HL, Kana TM, Geider RJ (2000) The effect of water motion on short-term 613 rates of photosynthesis by marine phytoplankton. Trends Plant Sci 5: 12-17 614

615 Mouget J-L, Tremblin G, Morant-Manceau A, Morançais M, Robert J-M (1999) 616 Long-term photoacclimation of Haslea ostrearia (Bacillariophyta): effect of 
617 irradiance on growth rates, pigment content and photosynthesis. Eur J Phycol 34: $618 \quad 109-115$

619

620 Mouget J-L, Tremblin G (2002) Suitability of the Fluorescence Monitoring System 621 (FMS, Hansatech) for measurement of photosynthetic characteristics in algae. Aquat 622 Bot 74: 219-231

623

624 Mouget J-L, Rosa P, Tremblin G (2004) Acclimation of Haslea ostrearia to light of 625 different spectral qualities - Confirmation of 'chromatic adaptation' in diatoms. J 626 Photoch Photobio B 75: 1-11

627

628 Olaizola M, Laroche J, Kolber Z, Falkowski PG (1994) Non-photochemical 629 fluorescence quenching and the diadinoxanthin cycle in a marine diatom. Photosynth $630 \quad$ Res 41: 357-370

631

632 Oxborough K, Hanlon ARM, Underwood GJC, Baker NR (2000) An instrument 633 capable of imaging chlorophyll a fluorescence from intact leaves at very low

634 irradiance and at cellular and subcellular levels of organization. Plant Cell Environ 20: $635 \quad 1473-1483$

636

637 Perkins RG, Underwood GJC, Brotas V, Snow G, Jesus B, Ribeiro L (2001) In situ 638 microphytobenthic primary production during low tide emersion in the Tagus estuary, 639 Portugal: production rates, carbon partitioning and vertical migration. Mar Ecol Prog 640 Ser 223: 101-112 
642 Perkins RG, Oxborough K, Hanlon ARM, Underwood GJC, Baker NR (2002) Can

643 chlorophyll fluorescence be used to estimate the rate of photosynthetic electron

644 transport within microphytobenthic biofilms? Mar Ecol Prog Ser 228: 47-56

645

646 Press WH, Teukolsky SA, Vetterling WT, Flannery BP (2003) Numerical recipes in

647 Fortran 77: The art of scientific computing. Cambridge University press, 933 pp

648

649 Ralph PJ, Gademann R, Larkum AWD, Schreiber U (1999) In situ underwater

650 measurements of photosynthetic activity of coral zooanthellae and other reef-dwelling

651 dinoflagellate endosymbionts. Mar Ecol Prog Ser 180: 139-147

652

653 Ralph PJ, Gademann R (2005) Rapid light curves: A powerful tool to assess

654 photosynthetic activity. Aquat Bot 82: 222-237

655

656

Ratkowski DA (1983) Non linear regression modeling. A unified practical approach.

657 Marcal Dekker INC., New-York, 276 pp

658

659 Raven JA, Geider RJ (2003). Adaptation, acclimation and regulation in algal

660 photosynthesis. In: Larkum AWD, Douglas S, Raven JA (eds) Photosynthesis in

661 Algae. Adv Photosynth Res 17, Kluwer Dordrecht, pp 385-412

662

663 Rodrigues MA, dos Santos CP, Young AJ, Strbac D, Hall DO (2002) A smaller and

664 impaired xanthophyll cycle makes the deeps sea macroalgae Laminaria abyssalis

665 (Phaeophyceae) highly sensitive to daylight when compared with shallow water

666 Laminaria digitata. J Phycol 38: 939-947 
668 Ruban AV, Lavaud J, Rousseau B, Guglielmi G, Horton P, Etienne A-L (2004) The 669 super-excess energy dissipation in diatom algae: comparative analysis with higher 670 plants. Photosynth Res 82: $165-175$

671

672 Sakshaug E, Bricaud A, Dandonneau Y, Falkowski P, Keifer D, Legendre L, Morel 673 A, Parslow J, Takahashi M (1997) Parameters of photosynthesis: definitions, theory 674 and interpretation of results. J Plankton Res 19:1637-1670

675

676 Schreiber U, Schliwa U, Bilger W (1986) Continuous recording of photochemical 677 chlorophyll fluorescence quenching with a new type of modulation fluorometer.

678 Photosynth Res 10: 51-62

679

680 Schreiber U, Gademann R, Ralph PJ, Larkum AWD (1997) Assessment of 681 photosynthetic performance of Prochloron in Lissoclinum patella in hospite by 682 chlorophyll fluorescence measurements. Plant Cell Physiol 38: 945-951

683

684 Serôdio J, da Silva JM, Catarino F (1997) Non-destructive tracing of migratory 685 rhythms of intertidal benthic microalgae using in vivo chlorophyll $a$ fluorescence. J 686 Phycol 33: 542-553

687

688 Serôdio J, Catarino F (2000) Modelling the primary productivity of intertidal 689 microphytobenthos: time scales of variability and effects of migratory rhythms. Mar 690 Ecol Prog Ser 192: 13-30

691 
692 Serôdio J (2003) A chlorophyll fluorescence index to estimate short-term rates of

693 photosynthesis by intertidal microphytobenthos. J Phycol 39: 33-46

694

695 Serôdio J, Viera S, Cruz S, Barroso F (2005a) Short-term variability in the 696 photosynthetic activity of microphytobenthos as detected by measuring light curves 697 using variable fluorescence. Mar Biol 146: 903-914

698

699 Serôdio J, Cruz S, Viera S and Brotas V (2005b) Non-photochemical quenching of 700 chlorophyll fluorescence and operation of the xanthophyll cycle in estuarine 701 microphytobenthos. J Exp Mar Biol Ecol in press

702

703 Ting CS, Owens TG (2003) Photochemical and non-photochemical fluorescence 704 quenching processes in the diatom Phaeodactylum tricornutum. Plant Physiol $705 \quad 101: 1323-1330$

706

707 Underwood GJC, Perkins RG, Consalvey MC, Hanlon ARM, Baker NR, Paterson 708 DM (2005) Patterns in microphytobenthic primary productivity: Species-specific 709 variation in migratory rhythms and photosynthesis in mixed-species biofilms. Limnol $710 \quad$ Oceanogr 50: 755-767

712 Underwood GJC, Kromkamp J (1999) Primary production by phytoplankton and 713 microphytobenthos in estuaries, p. 93-153. In Nedwell DB, Raffaelli DG (eds.) 714 Advances in Ecological Research: Estuaries 29. Academic Press, San Diego, USA 715 
717 Wilhelm C, Becker A, Toepel J, Vieler A, Rautenberger R (2004) Photophysiology 718 and primary production of phytoplankton in freshwater. Physiol Plantarum 120: 347$719 \quad 357$

720

721 Willemoës M, Monas E (1991) Relationship between growth irradiance and the 722 xanthophyll cycle pool in the diatom Nitzschia palea. Physiol Plantarum 83: 449-456 723

724 


\section{Figure Legends}

Figure 1. Rapid light response curves for N. phyllepta cultures grown at an irradiance of $100 \mu \mathrm{mol}$ photons $\mathrm{m}^{-2} \mathrm{~s}^{-1}$ and exposed to $1 \mathrm{~h}$ light acclimation period of low (A, 25 $\mu \mathrm{mol}$ photons $\mathrm{m}^{-2} \mathrm{~s}^{-1}$ ) or high $\left(\mathrm{B}, 400 \mu \mathrm{mol}\right.$ photons $\mathrm{m}^{-2} \mathrm{~s}^{-1}$ ) light. Light response curves were run with irradiance durations at each light curve increment of 10, 30 and $60 \mathrm{~s}$ and with either increasing (up) or decreasing (down) irradiance steps. Curves were constructed using the model of Eilers and Peeters (1988) followed by curve fitting following the Nelder-Mead model (Press et al., 2003).

Figure 2. Rapid light response curve parameters for light curves obtained using decreasing irradiance steps, shown in Fig. 1. (A) maximum electron transport rate, $\mathrm{rETR}_{\max }$; (B) maximum light use coefficient $(\alpha)$; (C) light saturation coefficient $\left(E_{\mathrm{k}}\right)$.

Figure 3. Non-sequential light response curves for $N$. phyllepta cultures grown at 100 $\mu$ mol photons $\mathrm{m}^{-2} \mathrm{~s}^{-1}$. Light curves were run using different sub-samples of culture for each light curve step and with irradiance durations of 10, 30 and $60 \mathrm{~s}$, followed by a final measurement when $F$ ' reached approximate 'steady-state' after 2 to 3 minutes. Curves were constructed using the model of Eilers and Peeters (1988) followed by curve fitting following the Nelder-Mead model (Press et al., 2003).

Figure 4. Non-sequential light response curves (mean \pm s.e., $\mathrm{n}=3$ ) for $N$. phyllepta cultures grown at an irradiance of $100 \mu \mathrm{mol}$ photons $\mathrm{m}^{-2} \mathrm{~s}^{-1}$ and exposed to $1 \mathrm{~h}$ light acclimation period of low (A, $25 \mu \mathrm{mol}$ photons $\left.\mathrm{m}^{-2} \mathrm{~s}^{-1}\right)$ or high $(\mathrm{B}, 400 \mu \mathrm{mol}$ photons $\mathrm{m}^{-2} \mathrm{~s}^{-1}$ ) light. Light curves were run using different sub-samples of culture for each light curve step, and with irradiance durations of 10, 30 and $60 \mathrm{~s}$, followed by a final 
751 measurement when $F$ ' reached approximate 'steady-state' after 2 to 3 minutes. Curves

752 were constructed using the model of Eilers and Peeters (1988) followed by curve

753 fitting following the Nelder-Mead model (Press et al., 2003).

755 Figure 5. Non-sequential light response curve parameters (mean \pm s.e., $n=3$ ) for 756 light curves obtained using different sub-samples of $N$. phyllepta culture for each 757 irradiance step, shown in Figure 4. (A) maximum electron transport rate, $\mathrm{rETR}_{\max }$; (B) 758 maximum light use coefficient $(\alpha)$; (C) light saturation coefficient $\left(E_{\mathrm{k}}\right)$.

760 Figure 6. Example of fluorescence kinetics obtained for a sub-sample of N. phyllepta 761 low-light culture used in a non-sequential light response curve step. Application of 762 saturating pulses are indicated by downward arrows after 10, 30 and $60 \mathrm{~s}$ and when $F^{\text {, }}$ 763 reached approximate 'steady-state' after 2 to 3 minutes. The actinic light increase was 764 from 25 to $370 \mu \mathrm{mol} \mathrm{m} \mathrm{m}^{-2}$.

766 Figure 7. Non-photochemical Chl $a$ fluorescence quenching (NPQ) calculated as $\left(F_{m}\right.$ $\left.767 F_{m}{ }^{\prime}\right) / F_{m}{ }^{\prime}$ for non-sequential light curves (Fig. 4) of $N$. phyllepta exposed to $1 \mathrm{~h}$ light 768 acclimation period of low $\left(\mathrm{A}, 25 \mu \mathrm{mol}\right.$ photons $\left.\mathrm{m}^{-2} \mathrm{~s}^{-1}\right)$ or high $(\mathrm{B}, 400 \mu \mathrm{mol}$ photons $769 \mathrm{~m}^{-2} \mathrm{~s}^{-1}$ ) light. NPQ was calculated using $F_{m}$ 'obtained from saturating pulses after 770 irradiance durations of 10,30 and $60 \mathrm{~s}$, followed by a final measurement when $F^{\prime}$ 771 reached approximate 'steady-state' after 2 to 3 minutes. The insert shows the change 772 in NPQ at 560 and $3200 \mu \mathrm{mol}$ photons $\mathrm{m}^{-2} \mathrm{~s}^{-1}$ over time. 
776

777

778

779

Figure 1

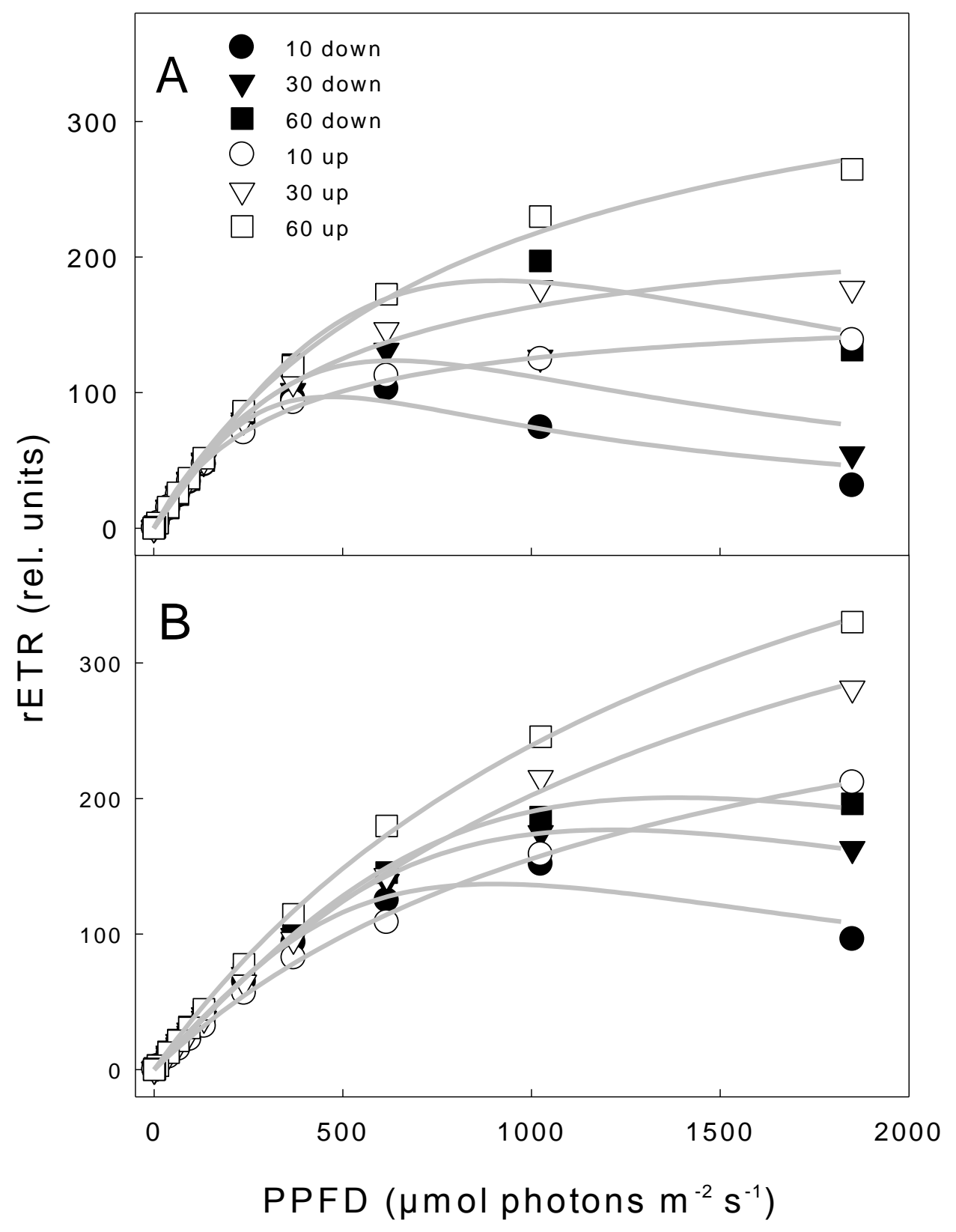


Figure 2

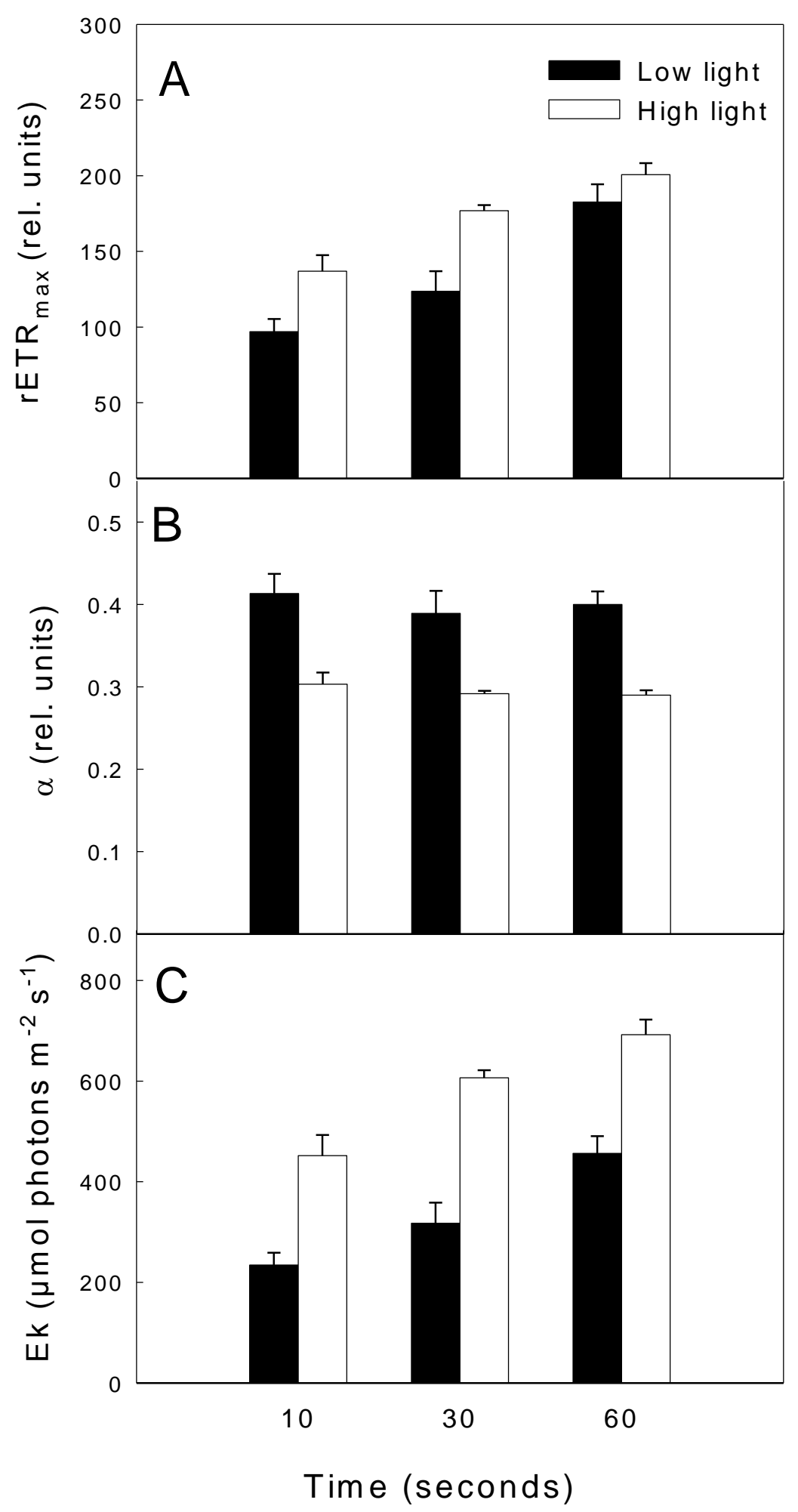


784

785

Figure 3

786

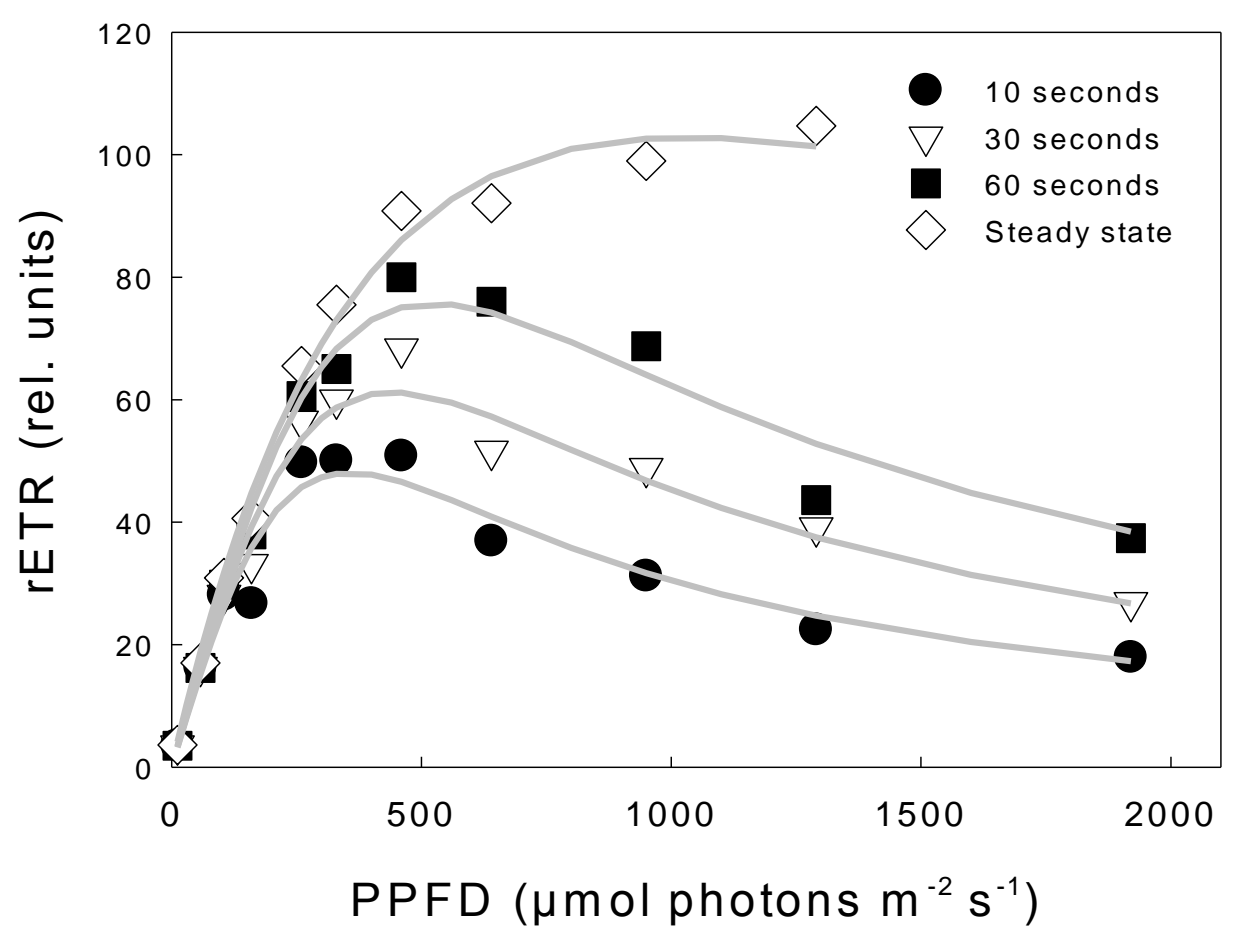

787

788 
789

790

Figure 4

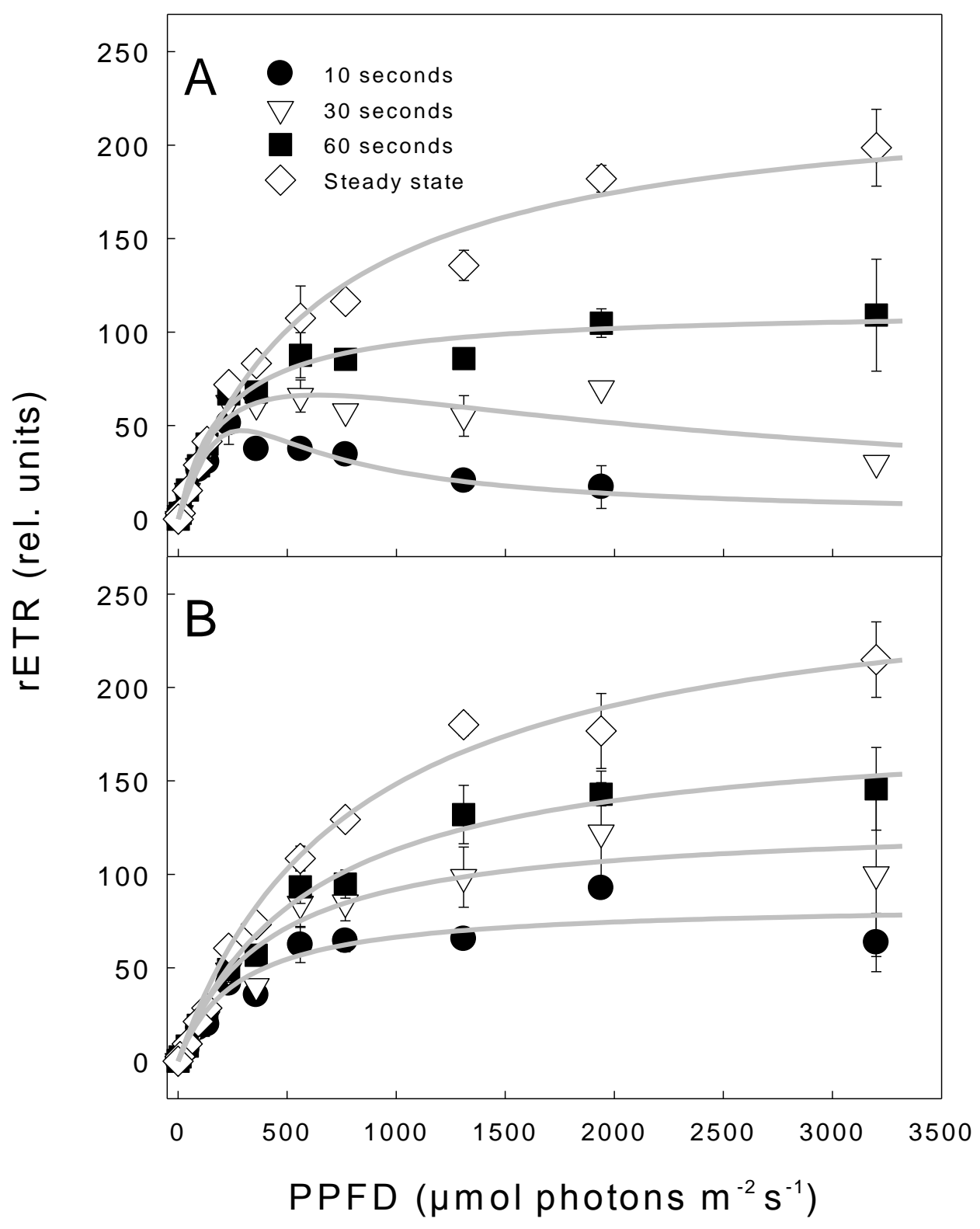


Figure 5

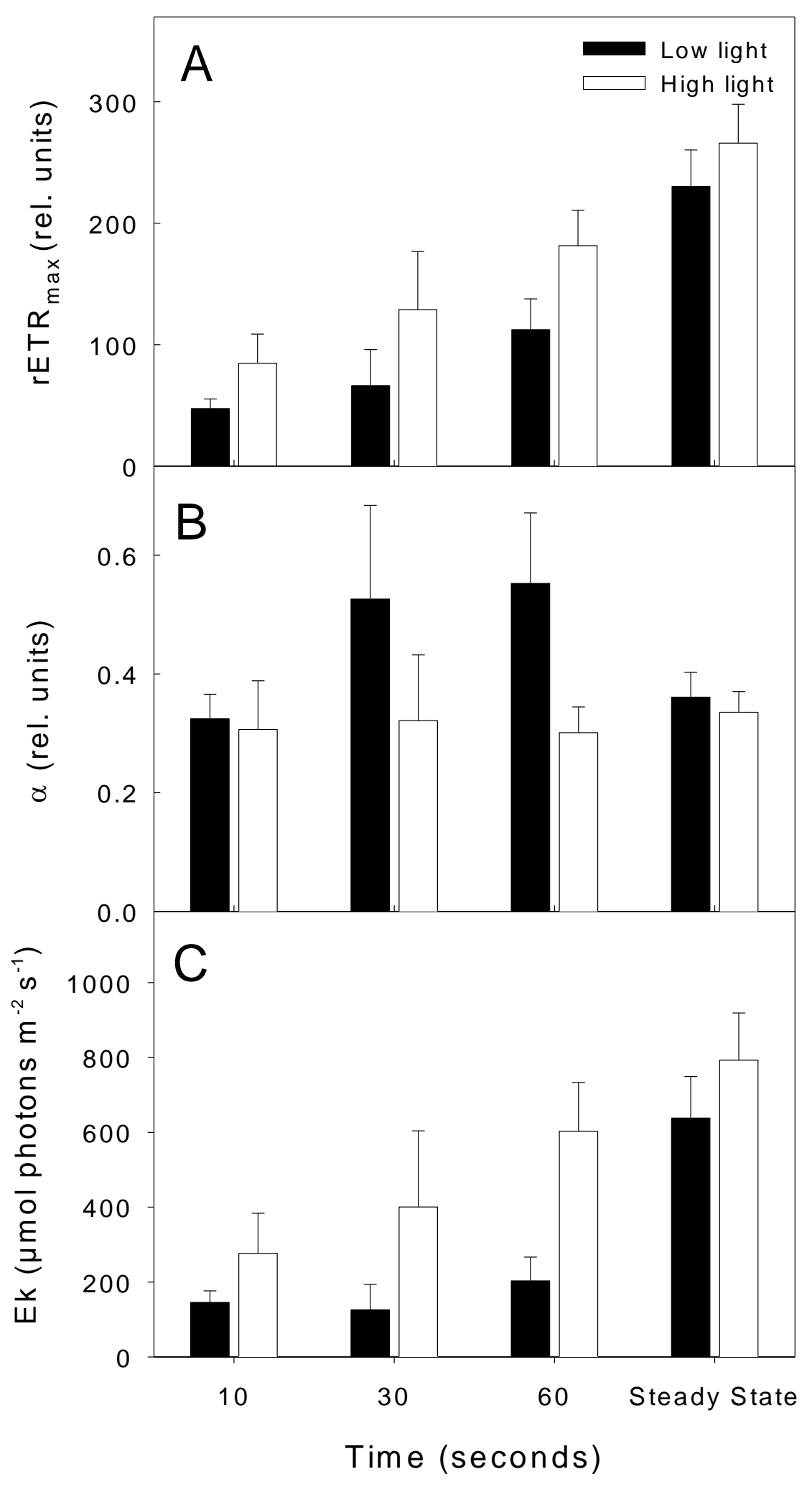


Figure 6

798

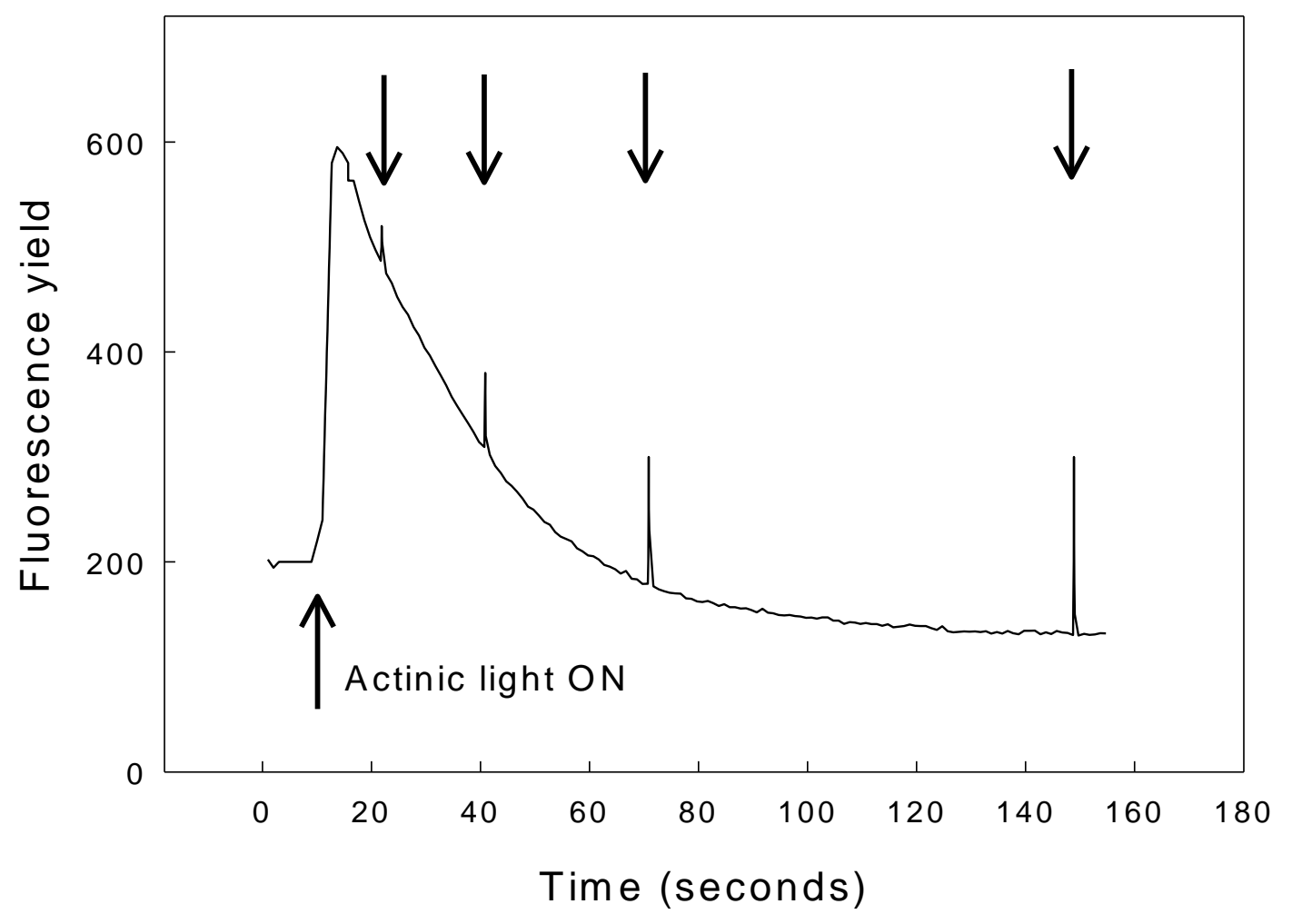

799

800

801

802

803

804 
805

Figure 7

806

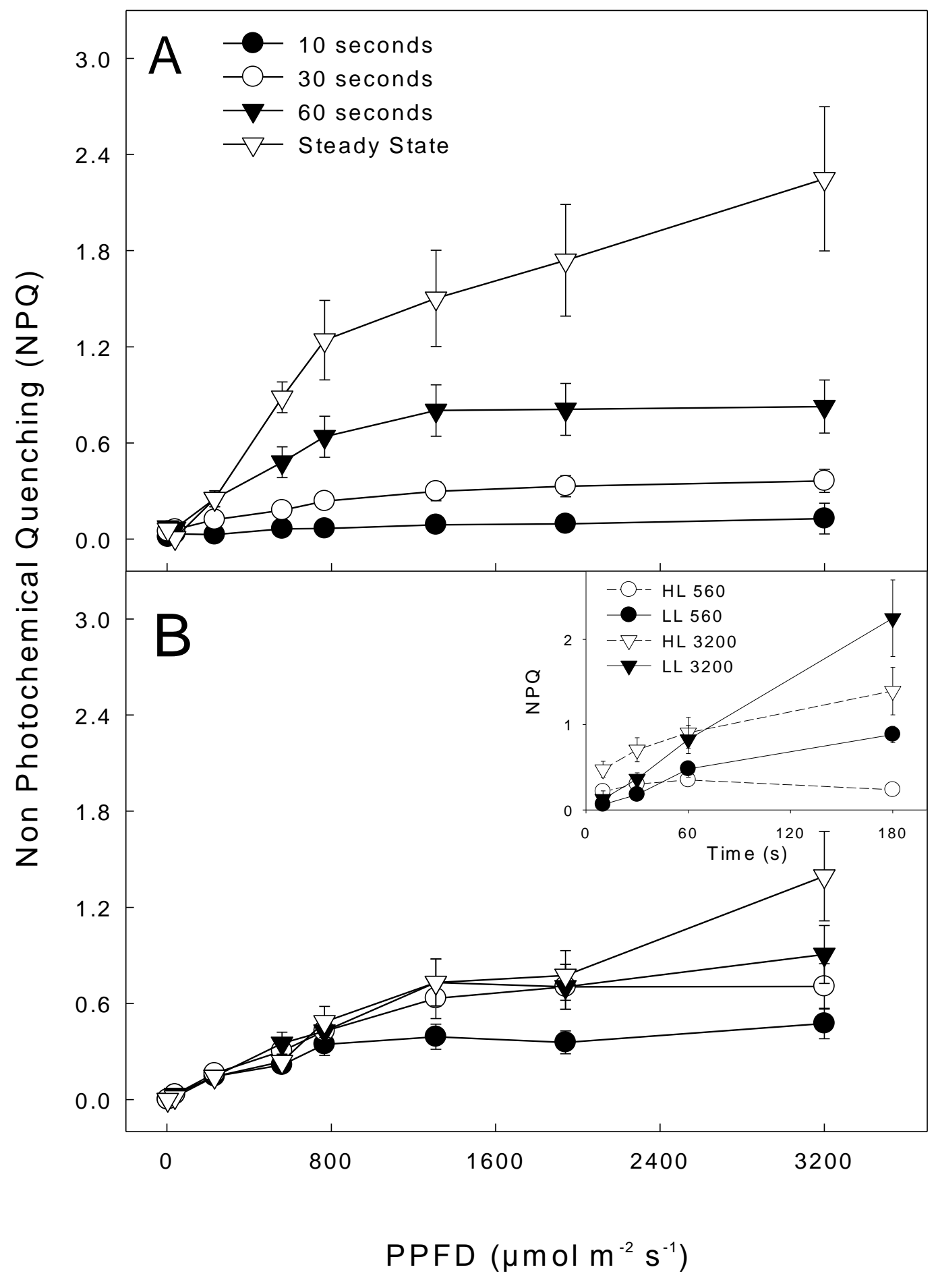

808 